\title{
Comparison of Neostigmine and Sugammadex Following Desflurane and Total Intravenous Anesthesia in the Elderly
}

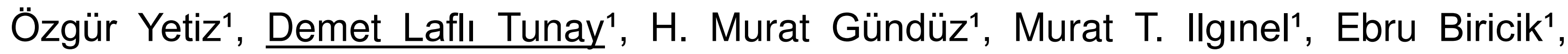 \\ Feride Karacaer ${ }^{1}$ \\ ${ }^{1}$ Cukurova University Faculty of Medicine, Department of Anesthesiology and \\ Reanimation, Adana, Turkey
}

Background and Goal of Study: The aim of this study is to compare the effects of neostigmine and sugammadex on recovery from anesthesia and reversal of neuromuscular blockage following desflurane and TIVA anesthesia applied to patients older than 65 years of age. Material and Methods: Eigthy ASA I-II patients older than 65 years of age, undergoing elective surgery with general anesthesia, with predicted surgery duration not exceeding 150 minutes, were included in this study. Patients were randomly divided into four groups. The first group was named with TIVA+sugammadex group (Group I), the second was TIVA+neostigmine group (Group II), the third was desflurane+sugammadex group (Group III) and the fourth was desfluran+neostigmine group (Group IV). Anesthesia maintenance was provided with total intravenous anesthesia (TIVA) in group I and II, and desflurane in group III and IV. Neuromuscular monitorisation was provided with acceleromyography displaying train-of-four (TOF) count. Reversal of neuromuscular blockage was achieved with sugammadex $(2 \mathrm{mg} / \mathrm{kg})$ in group I and III, and neostigmine in group II and IV at the reappearance of $\mathrm{T} 2$. All patients are also monitorized with bispectral index (BIS). The concentrations of anesthetic agents were adjusted to be
BIS value between 40-60. At the end of the surgery, duration of TOF ratio from 2 to 90, spontaneous respiration time, extubation time, duration of modified alderete score (MAS) $\geq 9$ was recorded for all patients. BIS values after the extubation were also recorded. Results: The time of T2 to T90 was obviously short in groups using sugammadex, regardless of the type of anesthesia. There was no difference between the groups at the time of return of spontaneous respiration and also extubation time except for between the TIVA+neostigmine and desflurane+neostigmine groups. In TIVA groups, the time to evaluate the MAS $\geq 9$ was found to be shorter than the other groups. Similarly, BIS values were higher at the spontaneous respiration and after extubation in TIVA groups.

Conclusion: It is concluded that the time to reverse neuromuscular blockade with $2 \mathrm{mg} / \mathrm{kg}$ sugammadex was significantly faster than neostigmine when they were used for decurarisation after general anesthesia with desflurane or TIVA in elderly, independent of the type of anesthesia. Additionally, postanesthetic recovery was more rapid in TIVA anesthesia compared with desflurane regardless of the type of recurarisation.

\begin{tabular}{|c|c|c|c|c|c|c|c|c|}
\hline \multirow{2}{*}{ Groups } & \multicolumn{2}{|c|}{$\mathrm{TOF} \geq 0.9$ (sec) } & \multicolumn{2}{|c|}{ BIS spontaneous respiration } & \multicolumn{2}{|c|}{ BIS extubation } & \multicolumn{2}{|c|}{ Modified Aldrete Score $\geq 9$ (sec) } \\
\hline & sec $\pm S D$ & $\mathrm{p}$ & Mean \pm SD & $\mathrm{p}$ & Mean \pm SD & $\mathrm{p}$ & sec $\pm S D$ & $\mathrm{p}$ \\
\hline \multirow{2}{*}{ TIVA sug-TIVA neos } & $162.50 \pm 70.91$ & \multirow{2}{*}{0.001} & $70.40 \pm 9.53$ & \multirow{2}{*}{0.603} & $81.75 \pm 8.92$ & \multirow{2}{*}{0.844} & $457.40 \pm 205.73$ & \multirow[b]{2}{*}{0.869} \\
\hline & $479.80 \pm 180.15$ & & $71.80 \pm 7.20$ & & $82.25 \pm 6.91$ & & $468.05 \pm 200.69$ & \\
\hline \multirow[b]{2}{*}{ TIVA sug-DES sug } & $162.50 \pm 70.91$ & \multirow[b]{2}{*}{0.754} & $70.40 \pm 9.53$ & \multirow[b]{2}{*}{0.001} & $81.75 \pm 8.93$ & \multirow[b]{2}{*}{0.001} & $457.40 \pm 205.73$ & \multirow[b]{2}{*}{0.032} \\
\hline & $153.256 \pm 105.26$ & & $59.40 \pm 9.15$ & & $68.75 \pm 11.42$ & & $637.95 \pm 298.05$ & \\
\hline \multirow{2}{*}{ TIVA sug-DES neos } & $162.50 \pm 70.91$ & \multirow[b]{2}{*}{0.001} & $70.40 \pm 9.53$ & \multirow[b]{2}{*}{0.003} & $81.75 \pm 8.93$ & \multirow[b]{2}{*}{0.005} & $457.40 \pm 205.73$ & \multirow[b]{2}{*}{0.001} \\
\hline & $617.50 \pm 458.18$ & & $58.65 \pm 13.38$ & & $70.95 \pm 13.70$ & & $756.00 \pm 274.79$ & \\
\hline \multirow{2}{*}{ TIVA neos-DES sug } & $479.80 \pm 180.15$ & \multirow[b]{2}{*}{0.001} & $71.80 \pm 7.20$ & \multirow[b]{2}{*}{0.001} & $82.25 \pm 6.91$ & \multirow[b]{2}{*}{0.001} & $468.05 \pm 200.69$ & \multirow[b]{2}{*}{0.041} \\
\hline & $153.26 \pm 105.26$ & & $59.40 \pm 9.15$ & & $68.75 \pm 11.42$ & & $637.95 \pm 298.05$ & \\
\hline \multirow{2}{*}{ TIVA neos-DES neos } & $479.80 \pm 180.15$ & \multirow[b]{2}{*}{0.219} & $71.80 \pm ., 20$ & \multirow[b]{2}{*}{0.001} & $82.25 \pm 6.91$ & \multirow[b]{2}{*}{0.002} & $468.05 \pm 200.69$ & \multirow{2}{*}{0.001} \\
\hline & $617,50 \pm 458.18$ & & $58.65 \pm 13.38$ & & $70.95 \pm 13.70$ & & $756.00 \pm 274.79$ & \\
\hline \multirow{2}{*}{ DES sug-DES neos } & $153.26 \pm 105.26$ & \multirow{2}{*}{0.001} & $59.40 \pm 9.15$ & \multirow{2}{*}{0.837} & $68.75 \pm 11.42$ & \multirow{2}{*}{0.585} & $637.95 \pm 298.05$ & \multirow{2}{*}{0.201} \\
\hline & $617.50 \pm 458.18$ & & $58.65 \pm 13.38$ & & $70.95 \pm 13.70$ & & $756.00 \pm 274.79$ & \\
\hline
\end{tabular}

